\title{
Examining mathematical discourse to understand in-service teachers' mathematical activities
}

\author{
Author: \\ Margot Berger ${ }^{1}$ \\ Affiliation: \\ ${ }^{1}$ School of Education, \\ University of the \\ Witwatersrand, South Africa \\ Correspondence to: \\ Margot Berger \\ Email: \\ margot.berger@wits.ac.za \\ Postal address: \\ Division of Mathematics \\ Education, School of \\ Education, University of the \\ Witwatersrand, Private Bag 3 \\ WITS 2050, South Africa
}

Dates:

Received: 17 Sept. 2012

Accepted: 27 Mar. 2013

Published: 19 Apr. 2013

How to cite this article: Berger, M. (2013). Examining mathematical discourse to understand in-service teachers' mathematical activities. Pythagoras, 34(1), Art. \#197, 10 pages. http://dx.doi.org/10.4102/ pythagoras.v34i1.197

\section{Copyright:}

(C) 2013. The Authors.

Licensee: AOSIS

OpenJournals. This work

is licensed under the

Creative Commons

Attribution License.
Read online:
In this article I use Sfard's theory of commognition to examine the surprising activities of a pair of in-service mathematics teachers in South Africa as they engaged in a particular mathematical task which allowed for, but did not prescribe, the use of GeoGebra. The (pre-calculus) task required students to examine a function at an undefined point and to decide whether a vertical asymptote is associated with this point or not. Using the different characteristics of mathematical discourse, I argue that the words that students use really matter and show how a change in one participant's use of the term 'vertical asymptote' constituted and reflected her learning. I also show how the other participant used imitation in a ritualised routine to get through the task. Furthermore I demonstrate how digital immigrants may resist the use of technology as the generator of legitimate mathematical objects.

\section{Introduction}

In this article I examine the activities of a pair of in-service mathematics teachers (the students) as they engage in a particular mathematical task which allows for, but does not prescribe, the use of GeoGebra. The task was part of a mathematics course in which the mathematical notion of a function was revisited. The course itself was part of a larger programme offered by a South African university to practising high-school mathematics teachers who wished to improve their mathematics teaching knowledge and their academic qualifications.

As will be seen, the students (i.e. the teachers) engage in the task in a surprising way: their use of GeoGebra is very limited and they use various mathematical terms such as 'asymptote' and 'undefined' very loosely.

In order to understand what is happening and why, I situate my analysis of the students' activities within Sfard's $(2007,2008)$ theory of commognition. The term 'commognition' (a mixture of the terms 'cognition' and 'communication') was introduced by Sfard (2008) to refer to a theory, developed by her, in which cognition and communication are regarded as different expressions of the same phenomenon. Specifically, cognition is an intrapersonal expression whereas communication is an interpersonal expression of a phenomenon. The theory draws both on Vygotsky and Wittgenstein and assumes a view of mathematics and of mathematics learning which resonates strongly with my own experiences of teaching and learning mathematics. Moreover it provides tight analytic constructs within which to examine and interpret mathematical activity. I use these constructs to show how 'words matter' and how a change in the discourse (in particular the use of the term 'vertical asymptote') affects the mathematical activity of the students. I also use this theory to show how the use of computers as a tool in mathematical learning may require an explicit rewriting of the rules of what counts as mathematical activity.

\section{Research goal}

The research I present here is a case study drawn from a larger project. A primary aim of the larger project is to examine ways in which in-service teachers are able to deepen their knowledge of fundamental mathematical concepts, such as 'function'.

In this article, I focus on:

- the ways in which two teachers engage in a task whose purposes is to enhance their knowledge of the distinction between removable discontinuities and vertical asymptotes.

- how the teachers deal with the affordances and limitations of graphing software, in this case, GeoGebra. This has important implications for their use of technology as a teaching tool.

These foci need to be contextualised within two constraints. The first is that all the students in the course were digital immigrants ${ }^{1}$ and had not used any educational software (such as GeoGebra)

1.'Digital immigrant' is the term coined by Prensky (2001) to refer to someone who was born before the widespread existence of digital technology. 
prior to this course. Secondly, the intended purpose of GeoGebra in the particular task was as a generator of graphs. That is, it was intended as a tool of amplification rather than of cognitive reorganisation (Pea, 1993).

\section{Background}

Although the focus of this article is on learning mathematics, rather than on what constitutes mathematics for teaching, it is important to situate the article within the broader debate around the type of mathematics that pre-service or in-service teachers need to know in order to be effective mathematics teachers (Ball, Thames \& Phelps, 2008; Davis \& Simmt, 2006; Stacey, 2008). Ball and her colleagues focus on the particular ways in which mathematics teachers need to engage with various mathematics procedures, representations and mathematical definitions in order to teach effectively. More generally, Silverman and Thompson (2008) argue that 'the work of teaching for understanding is predicated on coherent and generative understandings of the big mathematical ideas that make up the curriculum' (p. 501, my italics).

In the Southern African context, Pournara (2009) grapples with issues about what constitutes appropriate knowledge for pre-service mathematical teachers; Adler and Davis (2011) explore the constitution of mathematics for teaching in various South African education institutions. They show how different courses are differently constituted with different foci and they ask how the different types of courses they describe 'relate to teachers' learning from and experiences of mathematics for teaching and ultimately, the quality of their teaching' (p. 20). The article I present here goes a little way to addressing the first part of this question.

\section{The structure of the course}

In line with Silverman and Thompson (2008), I take it as axiomatic that mathematics teachers need to have a very good understanding of the fundamental ideas in mathematics, including mathematical concepts, definitions, procedures and connections to other fundamental ideas. In the South African situation (and probably in many other countries), this type of knowledge among practising high-school teachers cannot be assumed. For reasons born out of South African history, many high-school mathematics teachers in South Africa have a degree or diploma in education rather than in mathematics and these teachers' content knowledge is sometimes weak. Within the South African context, Fleisch (2008, p. 123) argues that small-scale studies point to very poor levels of conceptual knowledge and a large number of errors made by teachers in their own lessons. More specifically, Venkat and Adler (2012) point to problematic connections that several practising teachers in South African classrooms make between stated mathematics problems and their representations and the transformations of these representations. Cognisant of these weaknesses in teachers' knowledge and practice, our aim in this course was to revisit functions, extending and deepening teachers' understanding of this fundamental concept (Ma, 2010). Allied to this, the focus in the course was on the teachers as learners of mathematics (rather than as teachers of mathematics).
The course was structured as a part reading, part activity course. The class met once a week for a three-hour session over 11 weeks. Students were expected to study a specific chapter from the prescribed pre-calculus textbook (Sullivan, 2008) prior to their weekly session (this included doing examples at home). During the three-hour session, the class and lecturer discussed the topic and examples they had studied at home for the first hour. They were then presented with tasks around the topic which they did on their own or in pairs. Some of the tasks required the use of GeoGebra, others did not. I designed the structure of the course; my colleague, Lynn Bowie, taught most of the course and designed, selected or adapted most tasks.

\section{Commognitive framework Overview}

Sfard's (2008) theory of commognition is based on the premise that individual development is individualisation of 'patterned collective activity' (p. 93), and that thinking is individualised communication. In mathematics, patterned collective activity takes the form of mathematical discourse where a discourse is a special type of communication characterised by a range of permissible actions and reactions. Mathematical discourse is characterised by its words, visual mediators, routines and narratives (Ben-Zvi \& Sfard, 2007; Sfard, 2007). Commognition is primarily a participationist theory. Indeed learning only takes place through the individual's thoughtful participation in mathematical discourse. Accordingly mathematics learning is 'tantamount to modifying and extending one's mathematical discourse' (Sfard, 2007, p. 565).

According to Sfard, mathematics is an autopoietic system; that is, it creates its own objects. Thus mathematical objects are necessarily discursive objects. Sfard's notion of mathematical discourse derives directly from this ontological view of mathematics and the power of her framework lies in the connections it makes between this ontological perspective and the ways learners engage in the discourse. The foundational basis of Sfard's mathematical discourse theory contrasts with other discourse theories which have developed from non-mathematical domains. Indeed I find the inner consistency and coherence of Sfard's framework (Sfard, 2008) most appealing for understanding mathematical activity. (This is not to deny that other discourse theories have been successfully used in the mathematics domain, for example, Morgan's, 2005, use of Fairclough's critical discourse analytic approach; Shreyar, Zolkower \& Perez's, 2010, use of Halliday's systemic functional linguistic analysis.)

Sfard (2008) and Ben-Yehuda, Lavy, Linchevski and Sfard (2005) have defined and illustrated the different components of mathematical discourse in the context of everyday and school mathematical activity. Viirman (2011), in Sweden, has used commognitive theory to examine the discourse of university mathematics lecturers teaching an undergraduate course on functions. However, the components of mathematical discourse have, as far as I know, not been elaborated to sites of teacher education. Since such contexts have their own peculiarities, I extend Sfard's descriptions to include such contexts where necessary. 


\section{Elements of mathematical discourse \\ Words}

The use, in specific ways, of certain words or expressions such as 'equal', 'function' and 'vertical asymptote' indicates that we have mathematical discourse. Although many of these words also appear in everyday discourse, their use in mathematical discourse (even school mathematical discourse) is well defined, albeit often implicitly. For example, in colloquial discourse we say: 'I ate half an apple' to indicate that we ate approximately half an apple. In mathematical discourse, we use the word 'half' to mean exactly half. For example, half of eight is four. Word use is very important in that the use of the word constitutes its meaning (Wittgenstein, cited in Sfard, 2007, p. 571). In the task below, we see how the pair of students use the term 'vertical asymptote' to refer to any point whose value is undefined. I show that this loose and incorrect use of the term both reflects and reinforces an unrefined notion of the meaning of the term by the students and that a change in its use is necessary for distinguishing between a vertical asymptote and a hole (i.e. a removable discontinuity). Sfard (2008) calls the process of associating one name with several seemingly different mathematical objects 'saming'. Saming, if applied to discursive objects that are all realisations of the same signifier, is part of the process of the learner's construction of a new mathematical object. In the vignette below, students 'same' two objects which are not the same. These objects subsequently need to be 'unsamed'.

\section{Visual mediators}

Visual mediators are visible objects such as symbols, graphs and diagrams which participants in a mathematical discourse use to identify the objects of their thinking or communication and to bring these objects into focus. Sfard (2008) distinguishes between iconic mediators (such as graphs and pictures), symbolic mediators and concrete mediators (such as beads of an abacus). The use of these visual mediators constitutes mathematical thinking or communication and visual mediators are used as objects with which to think or communicate. In a GeoGebra context, it is fairly easy to generate graphs of various functions which can then serve as visual mediators. However, graphs generated by GeoGebra (and most other graphical software) may not reveal key aspects, such as removable discontinuities, of the function. In the task below, the students use hand-drawn graphs in which removable discontinuities may be represented by a hole rather than computer-generated graphs in which the discontinuities are hidden.

\section{Narratives}

Narrative is any text, spoken or written, that is 'framed as a description of objects, of relations between objects, or processes with or by objects' (Sfard, 2008, p. 300). Narratives are subject to endorsement and may be labelled 'true' or 'false'. Within formal mathematical discourse, the narratives that are approved by the academic mathematical community (according to specific, well-regulated rules) are called mathematical theories. These theories consist of various discursive objects such as axioms, theorems and definitions.
The rules of endorsement for school mathematics are often different from the rules of endorsement for more formal mathematics. For example, the statement 'the sum of angles in a triangle is always $180^{\circ}$ is true within school academic discourse (in which the axioms of Euclidean geometry form the backdrop). Within a more formal mathematical discourse, where hyperbolic geometry and spherical geometry are admitted, the statement is not necessarily true. Within the context of computer-based mathematical learning, mathematical narratives may be positively endorsed only if they conform to the traditional mathematical narratives (be it school or more formal academic mathematics).

\section{Routines}

A routine is a repetitive and well-defined discursive pattern. A routine may be a procedure; it may also be a practice (RAND Mathematics Study Panel, 2003) such as generalising, justifying or endorsing (or rejecting) mathematical narratives. Routines are regulated by certain rules; these may be rules about the objects in the discourse (object-level rules) or rules about the discourse itself (meta-rules), for example rules for what constitutes an acceptable proof. Sfard (2008) also distinguishes between the how of a routine, that is, the set of meta-rules that constrain the course of action, and the when (applicability conditions) of a routine, that is, the set of meta-rules that constrain or determine when it is appropriate to use a particular routine. In the vignette below we see the difficulty that students have with the 'when' of using GeoGebra for their mathematical routines.

Computer-generated routines themselves require further scrutiny. That is, certain algorithmic routines are easily executed by the software; however, the computer's routines do not always obey the rules of mathematical discourse. For example, GeoGebra (and most other graphical software) generates a continuous graph even if there are removable discontinuities in that function. Consequently the user needs to be aware of how to interpret the computer output so that it is compatible with endorsed mathematical narratives.

Sfard (2008) usefully distinguishes between three different types of routines: explorations, rituals and deeds, each of which is distinguished by its own set of goals. Explorations are routines whose purpose is to produce or verify an endorsable or endorsed narrative. For example, routines of solving equations, of proving a mathematical result, or of generating and investigating a mathematical conjecture are explorations. In the task below, students were expected to embark on a set of explorations in order to substantiate the definition of a 'vertical asymptote' and to determine the existence or not of a vertical asymptote at a particular point. A ritual is a routine whose goal is social approval. This is usually through the participant aligning her mathematical activity with other people's routines. Rituals involve imitation of others' routines; as such they may be a very important part of mathematical learning. Echoing Vygotsky (1978), Sfard (2008) argues that a ritual is the form that routines take in the zone of proximal development 
(p. 253). Arguably we can identify ritualised routines in the episode below. Finally, deeds are routines whose purpose is a change in objects, not just in narratives (as in the case of explorations). So for example, a child may be able to divide an actual set of six cookies amongst 12 children (a deed) although she may not be able to formulate or execute $12 \div 6$. In the GeoGebra environment, a task which involves the use of a slider to change the value of a parameter and hence a graph may constitute a deed.

\section{Vignette and its background}

In this vignette, a pair of students, Eva and Tom, work on a mathematical task in which they are expected to recognise the presence or not of a vertical asymptote at a point of a particular function. As mentioned previously, the course was designed as a reading and self-study course and prior to this particular session, students were assigned self-study readings and activities from the textbook relating to rational functions. Vertical asymptotes (definition plus symbolic and graphical exemplars of these) were part of this text as were removable discontinuities (which are called 'holes' in the textbook). Vertical asymptotes are also part of the school syllabus and so students (who were teachers) should have been familiar with this notion. Non-removable discontinuities are not part of the school curriculum but, as indicated, these should have been studied in the readings prior to this session. In addition, the students discussed examples of functions with vertical asymptotes in the first part of the session (prior to the task) although in this discussion, these vertical asymptotes were not directly related to their definition.

Eva has a BSc degree with a postgraduate diploma in education; Tom has a degree in education. In an earlier survey Eva claims to use the computer often and is very confident in its use; in contrast, Tom claims that he does not use a computer often, but he is confident, as opposed to 'very confident', in its use. Neither Tom nor Eva has used a computer in the learning or teaching of mathematics. Eva does very well in the course; she obtains $87 \%$ in mid-semester test. Tom is one of the weakest students in the class and he obtains $34 \%$ in the mid-semester mathematics test.

In this vignette, the students were audio taped and their work was screen recorded as they worked on a task that was given to the entire class to work on in pairs. The researcher sat just outside the room in which the students were working, walking in periodically to observe what was happening. The pairs of students were told that they must treat this as a normal classroom session and that they could ask the researcher any questions as they would in a classroom setting.

\section{Task}

The task was given as an instruction to do a particular question in the prescribed textbook (see Figure 1). Students were told that they could use GeoGebra if they wanted to. In addition, the warning: 'Be careful. GeoGebra isn't perfect here' was offered. The vignette took place during the sixth week of the class.

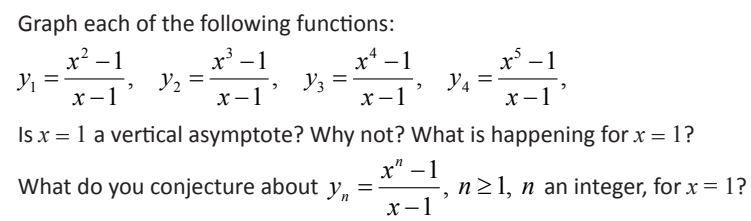

Source: Sullivan, M. (2008). Precalculus. (8th edn.). Upper Saddle River, NJ: Pearson Education International

FIGURE 1: The task.

\section{Pedagogical purpose of task}

This task can be done analytically. However, given explicit instructions to graph the functions it was expected that students would generate graphs of each function with GeoGebra (before or after algebraic simplification) or by hand (after algebraic simplification). For example, with respect to $y_{1}$, we expected students to use GeoGebra to sketch $y_{1}$ directly and to observe from the GeoGebra sketch that the graph of $y_{1}$ the straight line $y_{1}=x+1$.

Consequent to this, we expected them to write something like:

$$
y_{1}=\frac{x^{2}-1}{x-1}=\frac{(x-1)(x+1)}{x-1}=x+1, x \neq 1 .
$$

Alternatively, we expected students to first simplify $y_{1}$ to get $y_{1}=\frac{x^{2}-1}{x-1}=x+1, x \neq 1$; after this they could draw $y_{1}=x+1$ by hand, leaving a hole at $x=1$.

We expected them to work similarly for $y_{2}$ (a second degree equation). Given the cumbersome nature of drawing a cubic or quartic equation by hand, we expected students to use GeoGebra to sketch $y_{3}$ and $y_{4}$. Whether the graphs were hand drawn or computer generated, it was hoped that students would notice that each function was not defined at $x=1$ but that by cancelling the factor $(x-1)$ in the numerator and denominator, the problematic point, $x=1$, could be removed. Graphically this would be depicted by a hole at $x=1$ (they could draw this on a printout of the graph). Alternatively, they could use a theorem (the endorsed narrative) about the location of a vertical asymptote as given in their precalculus textbook (Sullivan, 2008, p. 188) to decide that none of the given functions had a vertical asymptote at $x=1$, or elsewhere.

The theorem reads:

A rational function $R(x)=\frac{p(x)}{q(x)}$, in lowest terms, will have a vertical asymptote $x=r$ if $r$ is a real zero of the denominator $q(x)$. That is, if $x-r$ is a factor of the denominator $q(x)$ of a rational function $R(x)=\frac{p(x)}{q(x)}$, in lowest terms, $R(x)$ will have a vertical asymptote $x=r$.

Note that that since this was a pre-calculus course we did not expect students to know the language of discontinuities. Rather we expected them to speak of holes or functions not existing at a point. 


\section{Description and analysis}

In the boxes and descriptions below I show how the tools of discourse, that is, words and visual mediators (Sfard, 2008), evolve as the activity proceeds. I also include spoken mediators since not all mathematical activity is visually mediated. I also highlight evolving aspects of the forms and substance of discourse, that is, routines and narratives (Sfard, 2008), in the column 'Routines and narratives'. In the following section, Extending the Analysis, I organise the analysis in terms of the four characteristics of mathematical discourse. This leads to further insights into the students' activities.

\section{Saming the unsame and endorsing the meta-rule of hand sketching}

At the start of the task, Eva (E) and Tom (T) indicate that they will hand draw the graphs of the four functions and that they will use GeoGebra to check their graphs (line 3,6). Eva and Tom talk about having a vertical asymptote at $x=1$ (lines 10-12). Box 1 contains the relevant transcript.

\section{Representing an undefined point}

After a little discussion Eva writes the following: $y=\frac{x^{2}-1}{x-1}, f(x)=\frac{(x-1)(x+1)}{x-1}=x+1$. She does not write $x \neq 1$.
Tom then hand draws line $y=x+1$. On Eva's suggestion, but with full support from Tom, Tom draws a hole (a circle) at $x=1$ (lines 36-38). That is, Tom and Eva's sketch of $y_{1}$ is in line with the pedagogical expectations of the task. Tom, with implicit prior approval from Eva (lines 9-12), also draws a vertical line at $x=1$ to indicate a vertical asymptote (Figure 2). See Box 2 for the transcript relating to the representation of the discontinuity.

\section{Endorsing the meta-rule of hand sketching}

Eva and Tom then generate a plot of $y_{1}$ in GeoGebra, presumably to confirm their hand plot. Eva again notes that GeoGebra does not generate a discontinuous graph (line 39). Eva and Tom also note that GeoGebra does not draw an asymptote at $x=1$ (lines 40-42). Box 3 contains the pertinent transcript.

\section{Hand sketching $y_{2}$ and $y_{3}$}

When it comes to $y_{2}$, Eva simplifies the function algebraically; again she does not note that $x \neq 1$. She writes: $\frac{(x-1)\left(x^{2}+x+1\right)}{x-1}=x^{2}+x+1$. Eva and Tom then spend much time and energy hand drawing the resultant parabolas; they use calculus to find turning points. Tom hand draws the graph correctly with hole at $x=1$ (and also with vertical line at $x=1$ ). See Figure 2. Eva and Tom confirm their plot with GeoGebra.

BOX 1: Setting the scene: Saming and hand drawing.

\begin{tabular}{|c|c|c|c|c|}
\hline Line & Transcript & Mediator & Words & Routines and narratives \\
\hline 3. & $\begin{array}{l}\text { E: Right? OK. And they say be careful. GeoGebra isn't perfect here, } \\
\text { so let's see what happens. We will do it sketching first and then } \\
\text { we'll check on GeoGebra. Now if the question is: Graph each of } \\
\text { the following functions. So we'll have to take each one and graph } \\
\text { it, OK? }\end{array}$ & \multirow[t]{3}{*}{$\begin{array}{l}\text { Symbolic: Written } \\
\text { words of given task. }\end{array}$} & \multirow[t]{7}{*}{$\begin{array}{l}\text { E draws attention to the } \\
\text { statement that the computer- } \\
\text { generated graph is 'not perfect'. }\end{array}$} & $\begin{array}{l}\text { E endorses meta-rule of hand } \\
\text { sketching and use of GeoGebra } \\
\text { for checking. }\end{array}$ \\
\hline 4. & $\mathrm{~T}: y$ equals to & & & \multirow{2}{*}{$\begin{array}{l}E \text { and } T \text { focus on the given } \\
\text { function. }\end{array}$} \\
\hline 5. & $\mathrm{E} \& \mathrm{~T}: x$ squared minus 1 over $x$ minus 1 & & & \\
\hline 6. & $\begin{array}{l}\text { E: Right. Let's draw our system of axes. Drawing our system of } \\
\text { axes. }\end{array}$ & $\begin{array}{l}\text { Pencil-and-paper ( } p \& p) \\
\text { graph: Iconic }\end{array}$ & & $\begin{array}{l}\text { Decision to hand draw graphs is } \\
\text { implicit. }\end{array}$ \\
\hline 7. & T: And then $x$ won't be equals to & \multirow{6}{*}{$\begin{array}{l}\text { Symbolic: } \\
y_{1}=\frac{x^{2}-1}{x-1}\end{array}$} & & $\mathrm{~T}$ and $\mathrm{E}$ are both aware that $x \neq 1$. \\
\hline 8. & $E \& \mathrm{~T}: 1$ & & & \\
\hline 9. & E: OK, but & & & \\
\hline 10. & $\mathrm{~T}$ : That is our vertical & & \multirow{3}{*}{$\begin{array}{l}\text { Saming vertical asymptote with } \\
\text { point at which function does } \\
\text { not exist. }\end{array}$} & \multirow{3}{*}{$\begin{array}{l}\text { T introduces notion of 'vertical } \\
\text { asymptote' with full cooperation } \\
\text { from E. }\end{array}$} \\
\hline 11. & E: asymptote & & & \\
\hline 12. & T: Ja. & & & \\
\hline
\end{tabular}

BOX 2: Representing the removable discontinuity.

\begin{tabular}{|llll|}
\hline Line & Transcript & Mediator & Words \\
\hline 36. & $\begin{array}{l}\text { E: So what we're going to do is draw a non-coloured circle } \\
\text { through that. So that's the only value } x \text { is not going to take, right? }\end{array}$ & $\begin{array}{l}\text { Iconic: p\&p graph } \\
\text { 37. }\end{array}$ T: Yes. & $\begin{array}{l}\text { Use of term 'circle' to } \\
\text { graphically represent the } \\
\text { value at which function is not } \\
\text { defined. }\end{array}$ \\
38. & $\begin{array}{l}\text { E: So we're going to draw our circle, right? Right. And then } \\
\text { continue that graph. That's it. OK. }\end{array}$ & \\
\end{tabular}

BOX 3: GeoGebra does not draw asymptotes.

\begin{tabular}{|c|c|c|c|c|}
\hline Line & Transcript & Mediator & Words & Routines and narratives \\
\hline 39. & $\begin{array}{l}\text { E: But you see GeoGebra doesn't do that. Can you see that it's } \\
\text { like a continuous graph, né? }\end{array}$ & GeoGebra: Iconic & $\begin{array}{l}\text { Focussing on GeoGebra's } \\
\text { limitations. }\end{array}$ & $\begin{array}{l}\text { E again notes that GeoGebra does } \\
\text { not show the discontinuity. }\end{array}$ \\
\hline 40. & T: GeoGebra cannot draw the & & & Both $\mathrm{E}$ and $\mathrm{T}$ implicitly endorse \\
\hline 41. & $\mathrm{E}:$ the asymp & & & $\begin{array}{l}\text { notion that } x=1 \text { is a vertical } \\
\text { asymptote. }\end{array}$ \\
\hline 42. & $\mathrm{~T}$ : the asymptote & & & \\
\hline
\end{tabular}


Eva and Tom now use GeoGebra to generate a graph of $y_{3}$; however they ignore this GeoGebra-generated graph and draw the graph by hand. Eva factorises the expression $y_{3}=\frac{x^{4}-1}{x-1}$ to get $x^{3}+x^{2}+x+1$ and she and Tom expend much effort hand plotting the resultant cubic using calculus. As before, Tom hand draws the graph correctly with a gap at $x=1$ (and also with vertical line at $x=1$; see Figure 2).

\section{Saming two different mathematical objects}

Eva and Tom persist in talking and writing about $x=1$ as a vertical asymptote (e.g. line 310) whilst at the same time recognising that there is a gap at $x=1$ (line 312). Box 4 contains the relevant transcript.

\section{Unsaming two different mathematical objects}

Finally, near the end of the activity the researcher interrupts to ask if the students have any questions. Eva states her concern that GeoGebra is not perfect because the asymptote is 'not reflected when $x$ is equal to 1 ' (line 323). The researcher uses this opportunity to explain that for a vertical asymptote, one must have an expression in the form $\frac{a}{0}, a \neq 0$, in lowest terms. If the expression is in the form $\frac{0}{0}$, one has a hole. (In this pre-calculus course, 'hole' is the word used both in the textbook and by the researcher to refer to a removable discontinuity.) That is, the researcher (R) 'unsames' vertical asymptote and a point at which the function is not defined. Although it seems that Tom does not entirely accept this explanation (see Box 5, line 345, 348), Eva endorses it in a later episode (Box 6, line 406). The transcript for this episode is in Box 5.

\section{Saming two equivalent objects}

Importantly, the pair no longer speak of an 'asymptote' at $x=1$ when they hand draw $y_{4}$. Rather, Eva speaks of a 'hole' at $x=1$; Tom continues to speak of an 'open circle' (lines 406, 407 respectively). As before, they use GeoGebra to generate the graph of $y_{4}$, which they then ignore. And, as before, they hand plot the graph (Figure 2) using much effort and time. Box 6 contains the relevant transcript.

BOX 4: Saming 'point at which function is not defined', 'asymptote' and 'circle'.

\begin{tabular}{|llll|}
\hline Line & Transcript & Mediator & Words \\
\hline 310 & $\begin{array}{l}\text { E: But now again our asymptote is going to be at } x \text { is equal } \\
\text { to } 1 \text {, so it's not going pass through } x \text {. Our graph is not equal } \\
\text { to } 1 . x \text { will not equal to 1. }\end{array}$ & $\begin{array}{l}\text { Symbolic: Written function } \\
\text { is: }\end{array}$ & $\begin{array}{l}\text { Saming asymptote and point } \\
\text { at which function is not } \\
\text { defined. }\end{array}$ \\
311 & $\begin{array}{l}\text { T: This } 1 \ldots \text { you see. } \\
\text { E: Ja. So again when we're drawing the graph we're going to draw } \\
\text { an uncoloured circle there. }\end{array}$ & Iconic: p\&p graph & $\begin{array}{l}\text { Saming 'asymptote', 'point at } \\
\text { ahich function is not defined' } \\
\text { and 'circle'. }\end{array}$ \\
\end{tabular}

BOX 5: Researcher unsames 'vertical asymptote' and 'hole'.

\begin{tabular}{|c|c|c|c|c|}
\hline Line & Transcript & Mediator & Words & Routines and narratives \\
\hline 341 & R: So it's not actually an asymptote... & Verbal: spoken & $\begin{array}{l}\text { Unsaming 'asymptote' and } \\
\text { 'hole'. }\end{array}$ & $\begin{array}{l}\text { Researcher explains that the } \\
\text { point where function is not } \\
\text { defined is not an asymptote. }\end{array}$ \\
\hline 342 & E: Ja. & & & \\
\hline 343 & T: Ja, but I & & & T starts objecting. \\
\hline 344 & R: But it's a hole in the graph where $x$ equals 1 . & & $\begin{array}{l}\text { Use of word 'hole'; unsaming } \\
\text { 'asymptote' and 'hole'. }\end{array}$ & $\begin{array}{l}\text { Researcher introduces term } \\
\text { 'hole'. }\end{array}$ \\
\hline 345 & E: No need to draw it. & Verbal: spoken & & $\begin{array}{l}\text { E accepts that there is no } \\
\text { vertical asymptote at } x=1 \text {. }\end{array}$ \\
\hline 347 & R: Ja, ja. & & & \\
\hline 348 & $\mathrm{~T}$ : We can erase it? & Iconic: p\&p graph & & $\mathrm{T}$ is still unsure. \\
\hline 349 & $\begin{array}{l}\text { R: You can erase it. But that's where the GeoGebra doesn't show } \\
\text { the hole. }\end{array}$ & Iconic: GeoGebra & Use of word 'hole'. & \\
\hline 350 & E: Yes, ja. & & & $\begin{array}{l}\text { E accepts that graph does not } \\
\text { show hole. }\end{array}$ \\
\hline 351 & R: It doesn't show what's called the discontinuities. & & Saming 'hole' and 'discontinuity'. & \\
\hline
\end{tabular}

BOX 6: Eva implicitly sames 'hole' and 'removable discontinuity'.

\begin{tabular}{|c|c|c|c|c|}
\hline Line & Transcript & Mediator & Words & Routines and narratives \\
\hline 404 & $\mathrm{E}$ : And go past 1 , then go there. & Iconic: p\&p graph & & $\mathrm{T}$ is drawing $\mathrm{p} \& \mathrm{p}$ graph. \\
\hline 405 & T: Past this point. & & & \\
\hline 407 & T: An open circle there. & & $\begin{array}{l}\text { T does not unsame 'circle' } \\
\text { and 'hole'. }\end{array}$ & T still uses the term 'circle'. \\
\hline
\end{tabular}




\section{Creating an endorsed narrative}

Soon after this, Eva and Tom discuss their response to the question: 'Is $x=1$ a vertical asymptote? Why not? What is happening for $x=1$ ?' See Box 7 for the transcript of their discussion.

Unlike Eva, Tom never articulates the difference between a removable discontinuity (a 'hole') and an asymptote, and it is not clear whether he ever makes this distinction. Indeed, he only talks about the function not being defined at $x=1$ (lines 434, 436, 440). For Eva, the notion of 'undefined at a point' has different possible meanings: if we can cancel out terms which are zero at that point (line 444), we do not have a vertical asymptote. However, if we cannot perform this cancellation, we may have an asymptote. (I suggest that this latter statement is implicit in line 444.) Interestingly, Eva now talks of a 'hole' at $x=1$, whilst Tom continues to use the term 'circle'. I discuss this further in the section headed 'Extending the analysis'.

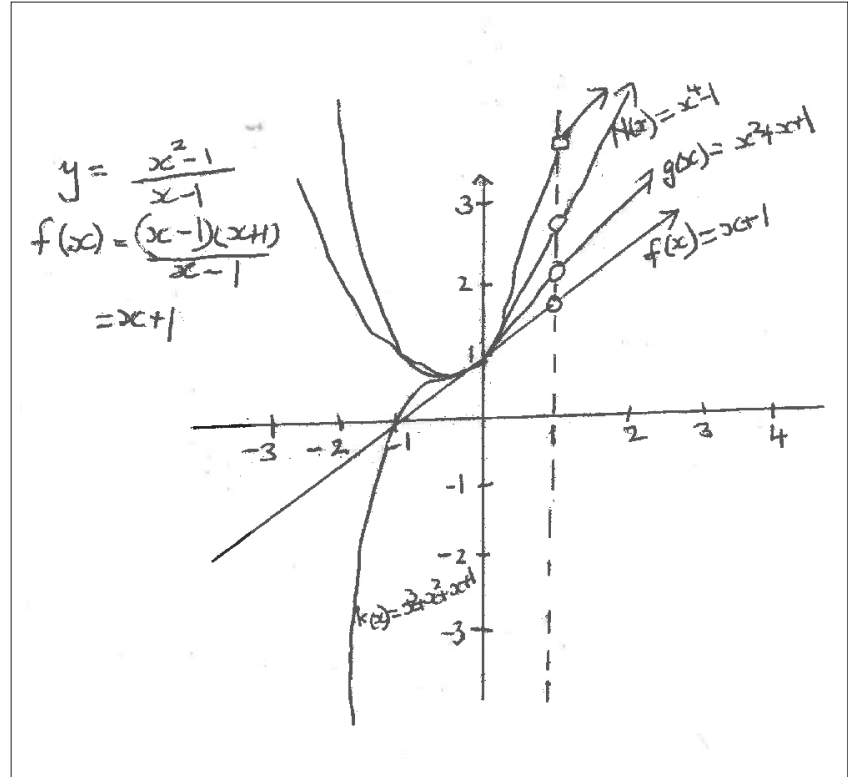

FIGURE 2: Hand plots of $y_{1}, y_{2}, y_{3}$ and $y_{4}$ by Eva and Tom

BOX 7: Eva creates endorsed narrative.

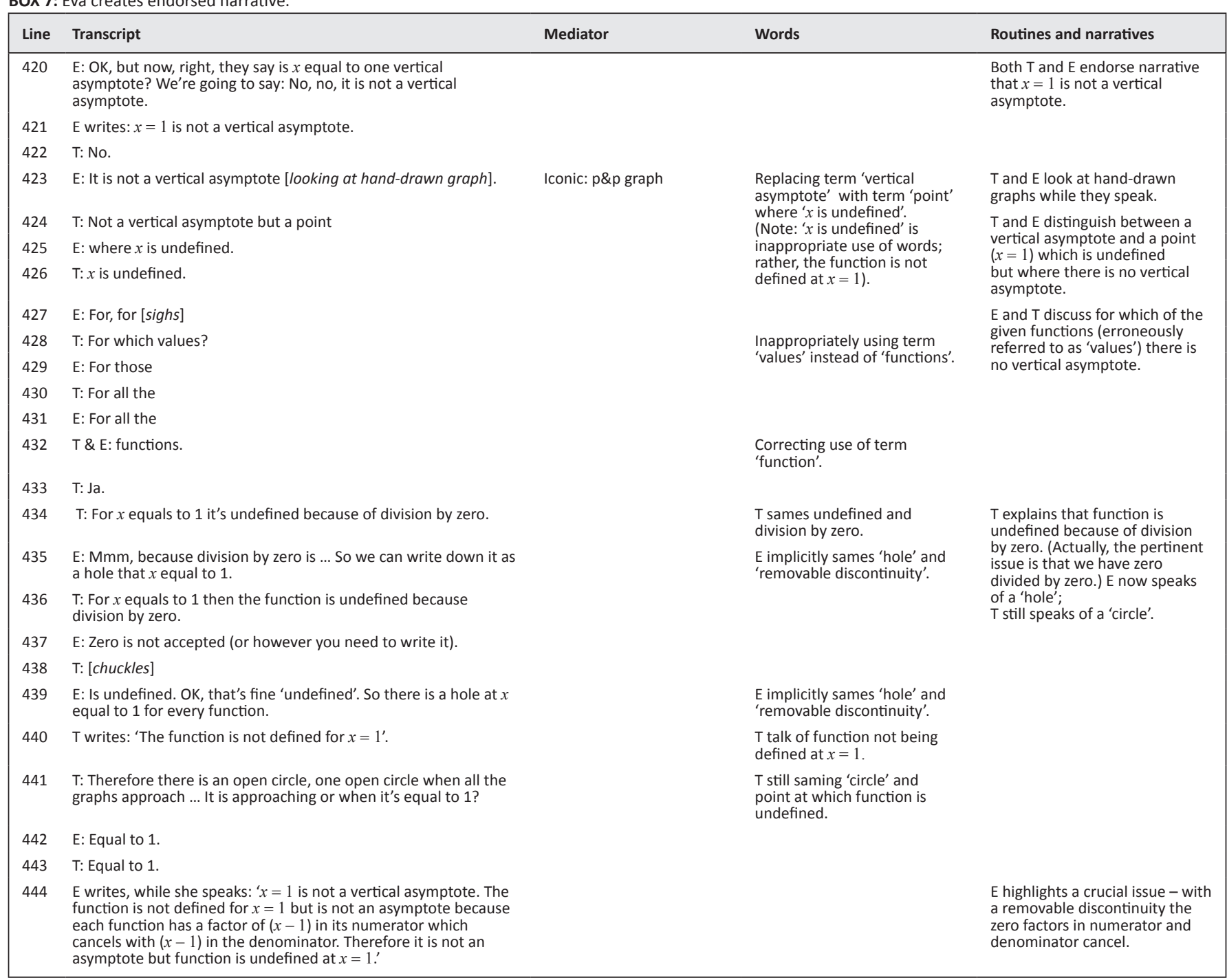




\section{Extending the analysis}

I use the four Sfardian characteristics of discourse to organise and thereby extend the above analysis.

\section{Endorsing narratives in a technological environment}

In this task, Eva and Tom do not exploit the affordances of GeoGebra as a graph sketching tool. As shown by the predominance of the category 'Iconic: paper and pencil graph' in the transcripts, they spend much time and effort in hand drawing each of the graphs and only use GeoGebra for verification. This is despite the fact that they are easily able to use GeoGebra to generate the graphs (evidenced by the ease with which they generate GeoGebra graphs for verification purposes). In this particular task, the graph that GeoGebra generates is not consistent with the officially endorsed narrative (wherein a removable discontinuity is represented by a hole). However, it was expected that students (forewarned to 'be careful. GeoGebra isn't perfect here') would recognise the limitations of the GeoGebragenerated graphs, but still use these computer-generated graphs as their primary visual mediator (largely to save time). But this is not what happened.

One possible reason for Eva and Tom's limited use of GeoGebra is an entrenched cultural attitude: mathematics is done by hand. Technology is there as a tool for confirmation of hand-done mathematics, but not for doing mathematics. Ontologically speaking, mathematical outputs produced by a computer are not part of the official mathematical narrative. Indeed Eva, who took the leading role (Sfard, 2007) in the discourse, declared right at the beginning of the task: 'We will do it sketching first and then we'll check on GeoGebra' (line 3). This attitude surprised me. This was the sixth week of this course and my colleague and I had stressed the value of using technology in doing mathematics: its narratives were endorsable, although some care had to be taken when interpreting its outputs.

Another possible reason for the privileging of hand-drawn graphs is in the students' reading of the caveat ('be careful. GeoGebra isn't perfect here'). This statement was intended to alert the students to the fact that GeoGebra did not reveal removable discontinuities in its graphs. But the statement may have reinforced the belief (discussed previously) that narratives of computer-generated mathematics are not consistent with the official mathematical narrative. Indeed Eva implicitly justifies the hand sketching of all graphs by invoking this cautionary statement at the beginning of the task (line 3).

It is important to note that the existence of the cautionary statement cannot be taken as the sole or even main reason why students privilege hand-drawn over computer-generated graphs. After all, the students use GeoGebra graphs to confirm their hand sketches and they are aware that the GeoGebra graph looks like their hand sketches, other than the lack of visible discontinuities: 'But you see GeoGebra doesn't do that. Can you see that it's like a continuous graph, né?' (line 39). Indeed I strongly propose that more technologically enculturated students would have printed GeoGebra graphs and then hand drawn holes or asymptotes.

\section{Visual mediation}

As mentioned above, Eva and Tom do not exploit the visual mediation that the GeoGebra graphs afford. Although GeoGebra generates a visual picture of the graph as if it were a continuous graph rather than a graph with a removable discontinuity at $x=1$, it was expected that students would use this graph together with the algebraic reasoning, $y_{1}=\frac{x^{2}-1}{x-1}=\frac{(x-1)(x+1)}{x-1}=x+1, x \neq 1$, to recognise that $x=1$ is a point at which the function is not defined. The students are clearly aware that the GeoGebra graph of $y_{1}$ deviates from the endorsed narrative (see e.g. lines 39-42), although they erroneously assume an asymptote at $x=1$.

The question is: Why do the students prefer to use handdrawn graphs rather than computer-generated graphs as visual mediators? Several reasons, some of which are discussed above, are feasible.

For example, it may be that they do not accept GeoGebra graphs as compatible with the endorsed mathematical narrative (as previously discussed), or it may be that they need to represent the value at which the function was not defined iconically. In this task, computer-generated graphs were not iconic and students lacked the experience of how to turn them into iconic mediators (print the GeoGebra graphs and draw a hole on the graph). So they preferred to use hand-drawn graphs in which a 'hole' could be directly and iconically represented.

With regard to the symbolic manipulation (an activity which is visually mediated), Eva is able to simplify the expressions $y_{1}, y_{2}, y_{3}$ and $y_{4}$ into polynomials which are easier to hand sketch (although this hand drawing is still very timeconsuming and effortful). Further discussion is provided under the heading 'Routines.'

\section{Words}

In the vignette we see how the students initially use the term 'vertical asymptote at a point' to describe a point at which a function is not defined. See, for example, lines 7-12, 39-42, 310 and 323, where the students assume that if a function is not defined at a point, it necessarily has a vertical asymptote at that point. Furthermore they consistently refer to the graphical representation of such a point as an (open) 'circle' (lines 38,312 ). In Sfard's terms they 'same' vertical asymptote with a point at which the function is not defined.

However, the researcher's modest intervention (lines 323-351)2, in which the difference between a hole (usually represented by an open circle) and a vertical asymptote is explained, triggers a distinct change in Eva's discourse. Indeed, post 2.Most of this transcript is not reproduced here. 
intervention Eva 'unsames' the terms 'not defined at a point' and 'vertical asymptote' (lines 423-426) and she unsames the term 'open circle' (used to represent a point through which there is a vertical asymptote) with 'hole' (which she uses to represent a removable discontinuity) (lines 406, 435, 439). She moves on to characterise the conditions which lead to a 'hole' (numerator and denominator cancel at zero, line 444). Mathematically speaking, neither 'hole' nor 'open circle' is a well-defined mathematical term. Nonetheless, by no longer speaking of an 'open circle' but rather speaking of a 'hole' Eva shifts her discourse from one in which 'not defined at a point', 'open circle' and 'asymptote' are samed to one in which these are unsamed; indeed, in the later discourse (lines 423-444) Eva produces an endorsed narrative in which she reserves the word 'hole' to refer to a removable discontinuity (line 444). In contrast there is little change in Tom's discourse; he still refers to the discontinuity as an 'open circle' (lines 407, 441) and he is uncertain as to whether he should erase the vertical asymptote at $x=1$ or not (lines 345,348$)$. Just to reiterate: although the term 'open circle' is as acceptable as the term 'hole' in pre-calculus discourse, 'open circle' was used, before the researcher's intervention, to signify a point at which there was an asymptote. Tom does not change his usage of this term and he does not sever this connection.

Furthermore, even though Tom and Eva no longer talk of an asymptote, Tom argues that: 'For $x$ equals to 1 it's undefined because of division by zero' (line 434). This is not correct: at $x=1$ the function is not defined because we have division of zero by zero. So unlike Eva, Tom does not change his discourse; nor does he produce an endorsed narrative around the notion of a removable discontinuity.

Implicit in the post-intervention discourse is a commognitive conflict. A commognitive conflict is a struggle, often implicit, which is the result of the concurrent use of two incompatible discourses. Eva uses the term 'undefined' to refer to a point at which the function is not defined (because of a zero in the numerator and denominator) and at which there is a removable discontinuity - a 'hole' (lines 406, 435, 439). In contrast, Tom uses the term 'undefined' to refer to a point at which a function is undefined because of division by zero (line 434). He calls such a point an 'open circle'. For learning to take place, the commognitive conflict needs to be acknowledged and resolved. Arguably it is the role of the teacher to support the resolution of such a conflict, rather than to bypass it, as in this vignette.

\section{Routines}

Eva and Tom are involved in several routines, each of which they repeat for $y_{1}, y_{2}, y_{3}$ and $y_{4}$. Specifically, they use hand graph sketching techniques to draw the four functions. These techniques include the routines of simplifying the original expression and routines involving point-by-point plotting and calculus. As has been discussed, in a context in which the students have access to a tool that they can use to sketch functions (albeit with some imperfections), executing routines to hand draw the graphs is inappropriate. In this case, I suggest that applicability conditions, that is, the rules that demarcate when a particular routine should be applied (Sfard, 2008, p. 209), are unclear to the students. Possible reasons for this non-appreciation of applicability conditions are given above (see 'Narratives' and 'Visual mediators').

Also, when simplifying the expressions for $y_{1}, y_{2}, y_{3}$ and $y_{4}$, the students do not explicitly state where the function is indeterminate. For this reason, the routines that they execute with regard to simplification contradict endorsed mathematical narratives. For example, Eva writes: $y_{2}=\frac{(x-1)\left(x^{2}+x+1\right)}{x-1}=\left(x^{2}+x+1\right)$. She does not indicate that $x \neq 1$ although she and Tom acknowledge that $x \neq 1$ several times, for example, lines 7-8, 36, 310, 407.

A further (non-endorsable) routine, extensively discussed above, involves the students' sketch of the vertical line $x=1$ to indicate a vertical asymptote at $x=1$ (see Figure 2). This drawing of an asymptote at $x=1$ reflects and reinforces the saming of the notion 'not defined at a point' and 'asymptote' as discussed above.

Arguably, Tom's discourse after the researcher's intervention (lines 421 onwards) has the quality of a ritual. That is, he is prepared to go along with Eva's explanation of what is happening at $x=1$ (lines 422-444), even though he does not seem convinced that there is no vertical asymptote at $x=1$ (evidenced by his checking whether he can erase the vertical asymptote from the sketch in lines 345, 348). Sfard (2008) argues that ritual is a necessary stage in routine development. Through the use of thoughtful imitation in routines the learner gains knowledge of the how of a routine. 'Imitation ... is the obvious, indeed, the only imaginable way to enter new discourse' (p. 250). In contrast, Eva's routines are primarily explorations. Her goal is to produce an endorsed narrative (which she does).

\section{Conclusion}

In this article I have used commognition (Sfard, 2008) to examine a pair of students' activities as they engage in a mathematical task in an in-service course for mathematics teachers in South Africa. I have found the framework and its characterisation of mathematical discourse very helpful in understanding certain surprising phenomena. In particular, I have used the analytic constructs to explain the reluctance of students to rely on computer-generated mathematical objects (e.g. graphs) as visual mediators. Suffice it to say that in courses involving technology and digital immigrants, it is essential for the lecturer or teacher to make explicit the new rules of mathematical discourse, in particular rules around when it is appropriate to use a computer in mathematical learning.

Another very important aspect of the mathematical activities, central to Sfard's theoretical framework and evidenced through empirical data here, is the crucial role that words 
play in mathematical discourse. That is, it really does matter how we use words when talking about mathematical phenomena. This is starkly shown by the students' unsaming of 'vertical asymptote' and 'point at which the function is undefined'. It is further demonstrated by Eva's embracing of a new word, 'hole', rather than 'open circle' (which was previously samed with 'vertical asymptote') to describe a removable discontinuity. Likewise, Tom's continued use of the term 'open circle' to describe a point at which the function is undefined both reflects and is constitutive of his non-distinction between different types of undefined points. This points to the importance of a teacher or researcher carefully listening to what students actually say and using their discourse as a way into their understandings.

Finally, considering learning as a change or extension of discourse, we can say that some learning has taken place: Eva has changed her discourse and Eva is able to distinguish between a vertical asymptote and a point at which a function is undefined. For Tom, the learning is less evident. Indeed I suggest that, for Tom, learning in this vignette is in the form of ritual and imitation.

\section{Acknowledgements}

Thank you to the National Research Foundation who supported the research underlying this article. Thank you to my colleague, Lynn Bowie, who taught this course and who developed or adapted or selected many tasks for this course.

\section{Competing interests}

I declare that I have no financial or personal relationship(s) which might have inappropriately influenced me in writing of this article.

\section{References}

Adler, J., \& Davis, Z. (2011). Modelling teaching in mathematics teacher education and the constitution of mathematics for teaching. In K. Ruthven, \& T. Rowland (Eds.) Mathematical knowledge in teaching (pp. 139-160). Dordrecht: Springer. http:// dx.doi.org/10.1007/978-90-481-9766-8

Ball, D., Thames, M.H., \& Phelps, G. (2008). Content knowledge for teaching: What makes it special? Journal of Teacher Education, 59, 389-407. http://dx.doi. org/10.1177/0022487108324554
Ben-Yehuda, M., Lavy, I., Linchevski, L., \& Sfard, A. (2005). Doing wrong with words: What bars students' access to arithmetical discourses. Journal for Research in Mathematics Education, 36(3), 176-247. Available from http://www.jstor.org/ Mathematics Ed
stable/30034835

Ben-Zvi, D., \& Sfard, A. (2007). Ariadne's thread, Daedalus' wings, and the learner's autonomy. Education \& Didactique, 1(3), 123-142. Available from http:// autonomy. Education \& Didactique,

Davis, B., \& Simmt, E. (2006). Mathematics-for-teaching: An ongoing investigation of the mathematics that teachers (need to) know. Educational Studies in of the mathematics that teachers (need to) know. Educational Studies
Mathematics, 61(3), 293-319. http://dx.doi.org/10.1007/s10649-006-2372-4

Fleisch, B. (2008). Primary education in crisis. Cape Town: Juta.

Ma, L. (2010). Knowing and teaching elementary mathematics. Teachers' understanding of fundamental mathematics in China and the United States. (anniversary edn.). New York, NY: Rouledge.

Morgan, C. (2005). Words, definitions and concepts in discourses of mathematics, teaching and learning. Language and Education, 19(2), 103-117. http://dx.doi. org/10.1080/09500780508668666

Pea, R. (1993). Practices of distributed intelligence and designs for education. In G. Salomon (Ed.), Distributed cognitions: Psychological and educational considerations (pp. 47-87). Cambridge: Cambridge University Press.

Pournara, C. (2009). Developing a new pre-service secondary mathematics teacher education programme: Principles for content selection and emergent tensions. Education as Change, 13(2), 293-307. http://dx.doi. org/10.1080/16823200903234836

Prensky, M. (2001). Digital natives, digital immigrants. On the Horizon, 9(5). http:// dx.doi.org/10.1108/10748120110424816

RAND Mathematics Study Panel (2003). Mathematical proficiency for all students: Towards a strategic research and development program in mathematics education/RAND Mathematics Study Panel, Deborah Loewenberg Ball, Chair. education/RAND Mathematics Study Panel, Deborah Loewenberg Ball, Chair. www.rand.org/pubs/monograph_reports/MR1643.htm

Sfard, A. (2007). When the rules of discourse change but nobody tells you: Making sense of mathematics learning from a commognitive standpoint. Journal of the Learning Sciences, 16(4), 565-613. http://dx.doi.org/10.1080/10508400701525253

Sfard, A. (2008). Thinking as communicating: Human development, the growth of discourses, and mathematizing. New York, NY: Cambridge University Press. http:// dx.doi.org/10.1017/CBO9780511499944

Shreyar, S., Zolkower, B., \& Perez, S. (2010). Thinking aloud together: A teacher's semiotic mediation of a whole-class conversation about percents. Educational Studies in Mathematics, 73, 21-53. http://dx.doi.org/10.1007/s10649-0099203-3

Silverman, J., \& Thompson, P.W. (2008). Toward a framework for the development of mathematical knowledge for teaching. Journal of Mathematics Teacher Education 11, 499-511. http://dx.doi.org/10.1007/s10857-008-9089-5

Stacey, K. (2008). Mathematics for seconday teaching. In P. Sullivan, \& T. Woods (Eds.) Knowledge and beliefs in mathematics teaching and teaching development, Vol. 1 (pp. 87-113). Rotterdam: Sense Publishers.

Sullivan, M. (2008). Precalculus. (8th edn.). Upper Saddle River, NJ: Pearson Education International.

Venkat, H., \& Adler, J. (2012). Coherence and connections in teachers' mathematical discourses in instruction. Pythagoras, 33(3), Art. \#188, 8 pages. http://dx.doi. org/10.4102/pythagoras.v33i3.188

Viirman, O. (2011). Discursive practices of two university teachers on the concept of 'linear transformation'. In B. Ubuz (Ed.), Proceedings of the 35th Conference of the International Group for the Psychology of Mathematics Education, Vol. 4 (pp. 313-320). Ankara: PME.

Vygotsky, L.S. (Ed.). (1978). Mind in society. Cambridge, MA: Harvard University Press. 